\title{
INVERTEBRADOS EDÁFICOS EM CULTURAS DE VERÃO E INVERNO NO NOROESTE DO RIO GRANDE DO SUL
}

\author{
Eduarda Mott Lucero' ${ }^{1}$, Renan Costa Beber Vieira², Ângela Denise Hübert Neufeld Vieira ${ }^{3 *}$
}

\begin{abstract}
RESUMO - A biota edáfica apresenta importância fundamental nos processos naturais. O clima, os tipos de culturas utilizadas e as práticas agrícolas adotadas podem ser limitantes para a diversidade biológica da comunidade desses invertebrados. A região noroeste do Rio Grande do Sul é uma das principais produtoras de grãos do Estado, entretanto, estudos avaliando a qualidade da biota edáfica são escassos nestes cultivos. Objetivou-se identificar os invertebrados edáficos em duas épocas sazonais distintas em áreas agrícolas cultivadas com diferentes tipos de coberturas vegetais em Santo Ângelo/RS. Para tanto, foram realizadas coletas em cinco diferentes coberturas vegetais (soja, milho e milheto no verão e trigo e consórcio de nabo forrageiro/azevém no inverno), utilizando armadilhas de queda "pitfall trap" por quatro dias no campo. Foram calculadas a abundância, a riqueza, a frequência relativa e os índices de diversidade para cada área avaliada. No total foram amostrados 11 diferentes ordens e 1.083 indivíduos, dos quais 1.051 foram artrópodes da classe Insecta, Arachnida e Entognatha. Observou-se que tanto a cobertura vegetal, quanto a sazonalidade influenciaram a comunidade de invertebrados edáficos no noroeste do Rio Grande do Sul. As áreas cultivadas com milho, milheto e nabo/azevém foram as mais diversas, enquanto que a área com trigo foi a mais dominada, apresentando uma alta abundância de Colembolla. No período do inverno predominaram os colêmbolos enquanto que no verão foram as formigas, principalmente no milheto e na soja.
\end{abstract}

Palavras chave: cobertura vegetal, fauna do solo, sazonalidade.

\section{EDAPHIC INVERTEBRATES IN SUMMER AND WINTER CROPS AT NORTHWEST OF RIO GRANDE DO SUL}

\begin{abstract}
Soil biota presents a fundamental importance in natural processes. The weather, the crops types and the agricultural practices adopted limiting the biological diversity of the terrestrial invertebrate community. The northwest of Rio Grande do Sul is one of the leading grain producers in the State, however, studies evaluating the quality of edaphic biota are scarce in these crops. This study aimed to identify the edaphic invertebrates community in two distinct seasonal seasons in agricultural areas cultivated with different vegetation cover in Santo Ângelo/RS. Therefore, sampling were performed in five different crops (soybeans, corn and millet in summer and wheat and turnip/ryegrass consortium in winter), using pitfall traps for four days in the field. The abundance, richness, relative frequency and diversity indexes were calculated for each area. In total, 11 different orders and 1,083 individuals were sampled, of which 1,051 were Arthropods of the Insecta, Arachnida and Entognatha class. The vegetation cover and the seasonality influenced the edaphic invertebrate community in the northwest of Rio Grande do Sul. The most diverse areas were corn, millet and forage turnip/ryegrass, while the most dominated was wheat, due to the abundance of Colembolla. In the winter period, the springtails were predominant, whereas in summer it was the ants, mainly in millet and soybean.
\end{abstract}

Keywords: seasonality, soil fauna, vegetable covering.

\footnotetext{
1 Universidade Regional Integrada do Alto Uruguai e das Missões. Rua Universidade das Missões, 464, CEP: 98.802-470, Santo Ângelo - RS. E-mail: dudaluceroo@gmail.com.

2 Universidade Federal da Fronteira Sul - UFFS. Rua Jacob Reinaldo Haupenthal, 1.580, São Pedro, CEP 97900-000, Cerro Largo - RS. E-mail: renan.vieira@uffs.edu.br.

3 Universidade Regional Integrada do Alto Uruguai e das Missões. Rua Universidade das Missões, 464, CEP: 98.802-470, Santo Ângelo - RS. E-mail: angelaneufeld@san.uri.br. *Autora correspondente.
} 


\section{INTRODUÇ̃̃O}

O solo é um ecossistema fundamental para a regulação dos fluxos biogeoquímicos na Terra pois, através de suas características químicas, físicas e biológicas, reincorpora e assimila matéria orgânica e nutrientes minerais. A biota do solo é composta por invertebrados e microrganismos, que são de fundamental importância para os processos naturais. Macro e microinveterbrados atuam na ciclagem de nutrientes através da quebra de materiais orgânicos, na regulação de comunidades biológicas por meio de suas redes tróficas e na estruturação do solo através de atividades de alimentação e escavação. Um ecossistema edáfico equilibrado mantém a produtividade dos conjuntos vegetais e o bom funcionamento da natureza e de seus processos biológicos (Moreira et al., 2013).

A diversidade biológica e a qualidade do solo são diretamente proporcionais. A fragmentação, decomposição e mineralização dos resíduos orgânicos dependem da fauna edáfica e favorecem a disponibilidade de nutrientes para plantas e outras espécies (Brown \& Sautter, 2009). Artrópodes são abundantes no solo e realizam um papel chave no funcionamento dos ecossistemas. Eles ocupam diversos níveis tróficos dentro da cadeia alimentar do ambiente edáfico e fora dele, o que influencia os fluxos de energia (Correia, 2002). Além disso, estes organismos atuam como engenheiros do ecossistema através de inúmeros processos como: estruturação do solo pela liberação de polímeros orgânicos durante seus processos metabólicos; aeração e revolvimento pela atividade de escavação de galerias e ninhos; incorporação de resíduos vegetais que diminuem a densidade do solo; decomposição e adição de matéria orgânica pela fragmentação inicial dos resíduos e aumento de sua área superficial específica (Höfer et al., 2001; Silva et al., 2006; Domínguez et al., 2018).

A qualidade do solo depende da interação positiva entre fatores físicos, químicos e biológicos nesse ecossistema. Quando as comunidades edáficas são simplificadas esses processos naturais tendem a diminuir ou desaparecer e os custos ambientais e socioeconômicos podem ser significativos (Altieri et al., 2003). A agricultura e as culturas utilizadas influenciam as propriedades do solo e causam mudanças nesse habitat (Calonego et al., 2012) e a comunidade de invertebrados edáficos responde a essas alterações (Wu \& Wang, 2019).

Solos mal manejados levam à seleção de grupos de artrópodes e causam redução na riqueza e diversidade da fauna edáfica (Nunes et al., 2012; Jiang et al., 2018). Essa menor diversidade traz como consequências a perda de atividades ecossistêmicas essenciais e a menor resistência e resiliência do ecossistema edáfico, resultando em queda na produção agrícola (Gatiboni et al., 2009). Solos bem manejados auxiliam na manutenção da diversidade de invertebrados principalmen- te devido a cobertura vegetal constante (Wu \& Wang, 2019). Este efeito é relacionado à disponibilidade de recursos para alimento e refúgio, além da vegetação afetar também outros parâmetros edáficos, como infiltração de água, evapotranspiração, erosão, agregação, aeração e perda ou adição de matéria orgânica e nutrientes (Silva et al., 2006).

Invertebrados edáficos são bioindicadores de qualidade do solo (Domínguez et al., 2018), pois são abundantes nesse ecossistema, desempenham uma grande variedade de funções essenciais e apresentam resposta rápida às mudanças ocorridas no seu habitat (Córdova et al., 2009). Desta maneira, o conhecimento sobre a diversidade desses grupos no ambiente agrícola fornece informações importantes sobre a sustentabilidade dos manejos adotados. Pesquisas dessa natureza na região noroeste do Rio Grande do Sul ainda são escassas e incompletas. Nessa perspectiva, o objetivo deste trabalho foi identificar a comunidade de invertebrados edáficos em duas épocas sazonais distintas em áreas agrícolas cultivadas com diferentes coberturas vegetais no município de Santo Ângelo/RS.

\section{MATERIAL E MÉTODOS}

\section{Localização e caracterização área de amostragem}

O estudo foi realizado no município de Santo Ângelo, noroeste do estado Rio Grande do Sul, em duas áreas agrícolas com diferentes tipos de coberturas vegetais sob as seguintes coordenadas: 28 $16^{\prime} 30.0^{\prime \prime} \mathrm{S}$

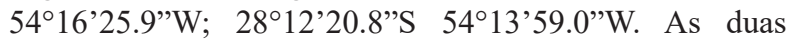
áreas agrícolas são cultivadas em plantio direto por mais de 20 anos e distanciam-se em aproximadamente $10 \mathrm{~km}$.

Santo Ângelo apresenta um clima subtropical úmido Cfa segundo a classificação de Köppen-Geiger (1937). A temperatura média anual em Santo Ângelo é 20,2 ${ }^{\circ} \mathrm{C}$. No mês mais quente (Janeiro) a temperatura média é de $25,3{ }^{\circ} \mathrm{C}$, enquanto que no mês mais frio (Julho) a média é de $15,1^{\circ} \mathrm{C}$. A pluviosidade média anual na cidade é de $1.818 \mathrm{~mm}$, com diferença de $50 \mathrm{~mm}$ entre a precipitação do mês mais seco e do mês mais chuvoso (IRGA, 2018). O solo das áreas avaliadas é classificado como Latossolo Vermelho distroférrico (Embrapa, 2018).

O estudo foi realizado em duas estações distintas, avaliando culturas de verão e culturas de inverno. No verão a coleta foi realizada na primeira quinzena de março de 2018 avaliando as culturas de milho (Zea mays L.), milheto (Pennisetum glaucum L.) e soja (Glycine max L. Merr.). No período do inverno a coleta foi realizada na segunda quinzena de agosto de 2018 avaliando as culturas de trigo 
(Triticum spp.) e o consórcio de nabo-forrageiro (Raphanus sativus L.) e azevém (Lolium multiflorum L.).

\section{Amostragem da fauna}

Para a amostragem dos invertebrados edáficos foram delimitadas em cada gleba com cobertura vegetal uma área de $180 \mathrm{~m}^{2}$ (15 $\mathrm{m}$ de comprimento e $12 \mathrm{~m}$ de largura), com base na homogeneidade amostral. Dentro de cada área foram instaladas quatro armadilhas "pitfall trap" adaptadas sem atrativos contendo $300 \mathrm{~mL}$ de álcool etílico 70\% (Antoniolli et al., 2006). As armadilhas foram dispostas em um grid quadrado centralizado com lado de 7 metros. As armadilhas permaneceram dispostas no local por quatro dias. Após o período de amostragem, os organismos coletados foram armazenados em potes plásticos de $250 \mathrm{~mL}$ contendo álcool etílico $70 \%$, sendo posteriormente triados e identificados a nível de ordem (Buzzi, 2013) no Laboratório de Zoologia da Universidade Regional Integrada do Alto Uruguai e das Missões (URI), Campus de Santo Ângelo.

Para caracterização das condições climáticas foram acompanhados os dados de precipitação acumulada e de temperatura do ar máxima e mínima durante os meses antecedentes às coletas (fevereiro e julho) e nos meses de avaliação da fauna edáfica (março e agosto), a fim de retratar o ambiente de desenvolvimento da comunidade biológica (Figura 1). Os dados meteorológicos do município de Santo Ângelo/RS foram obtidos através do Instituto Rio Grandense de Arroz (IRGA, 2018).

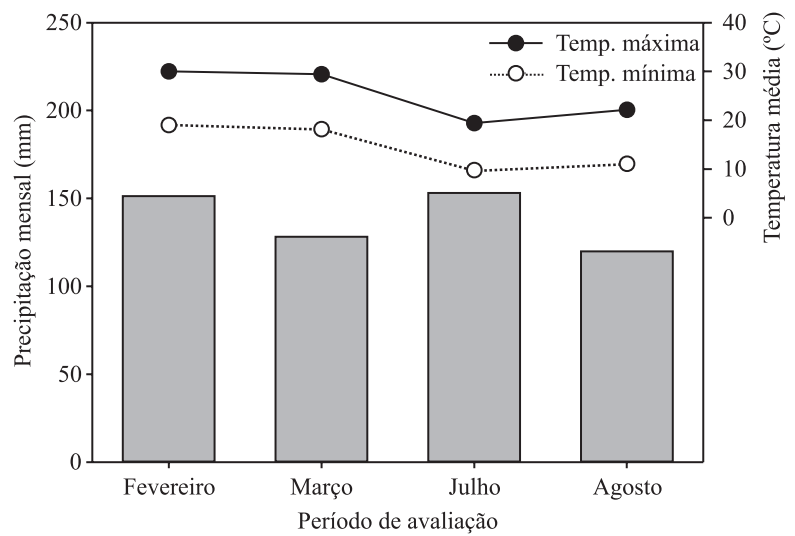

Figura 1 - Temperatura do ar máxima e mínima e precipitação acumulada nos meses de amostragem (Março e Agosto/2018) e os meses que antecederam as amostragens (Fevereiro e Julho/2018) de invertebrados edáficos em cinco diferentes coberturas vegetais agrícolas em dois períodos sazonais no município de Santo Ângelo/RS.

\section{Análises estatísticas}

As análises dos dados se deram a partir da soma dos espécimes de cada ordem amostrados nas quatro armadilhas em cada cobertura vegetal. Foram calculadas a frequência relativa, a abundância total, a riqueza e a diversidade dos organismos coletados em cada tipo de cobertura vegetal (Odum and Barrett, 2007). Os índices de diversidade de Shannon, de dominância de Simpson e de equitabilidade de Pielou foram calculados pelo software PAST versão 2.17 (Palaeontological Statistics) (Hammer et al., 2001) para comparar a diversidade entre os tratamentos.

\section{RESULTADOS E DISCUSSÃo}

A amostragem dos organismos da fauna edáfica nas cinco culturas agrícolas totalizou 1.083 indivíduos (Tabela 1). A abundância média de organismos nas culturas de inverno foi de 262 indivíduos, enquanto que nas coberturas vegetais de verão encontrou-se em média 186 indivíduos. Quando avaliada a riqueza, observouse que das 11 ordens amostradas somente cinco foram encontradas tanto no inverno quanto no verão, sendo essas Hymenoptera, Diptera, Coleoptera, Orthoptera e Pulmonata. Independente da cultura avaliada, a variação sazonal entre os períodos amostrais de $8^{\circ} \mathrm{C}$ superior nos meses de verão (Figura 1), influenciou a diversidade da comunidade edáfica, corroborando com diversos estudos (Elie et al., 2018; Yin et al., 2018; Wu \& Wang, 2019).

As diferentes coberturas vegetais influenciaram a comunidade de invertebrados (Tabela 1). A diversidade das comunidades de artrópodes está relacionada à diversidade da comunidade vegetal do habitat, pois em ambientes mais complexos há maior oferta de nichos ecológicos, refúgios contra predadores e disponibilidade de sítios para nidificação (Vieira \& Mendel, 2002; Wu \& Wang, 2019). Além disso, o sistema de uso do solo também interfere diretamente sobre a diversidade da fauna edáfica, assim como o nível de intervenção antrópica (Rosa et al., 2015).

A ordem Colembolla foi a mais abundante, embora tenha sido encontrada somente em duas das cinco coberturas vegetais avaliadas. Esse grupo totalizou uma frequência de $89 \%$ no trigo e $26 \%$ no consórcio de nabo/ azevém (Figura 2). Os colêmbolos são um dos grupos mais abundantes da mesofauna edáfica. Sua importância ecológica é variada, pois constituem uma fonte de alimento para predadores como as aranhas e coleópteros (Silva et al., 2013), apresentam papel fundamental na decomposição da matéria orgânica, na ciclagem de nutrientes e atuam no 
controle biológico (Moreira et al., 2010). Por possuírem alta sensibilidade às mudanças nas condições ambientais onde estão inseridos são considerados bioindicadores de qualidade ambiental do solo (Damé et al., 1996).

Tabela 1 - Abundância total dos táxons de invertebrados edáficos amostrados em cinco diferentes coberturas vegetais agrícolas em dois períodos sazonais (milheto, milho, soja no verão e trigo e nabo/azevém no inverno) no município de Santo Ângelo/RS.

\begin{tabular}{|c|c|c|c|c|c|c|}
\hline \multirow{2}{*}{ Táxon } & \multicolumn{3}{|c|}{ 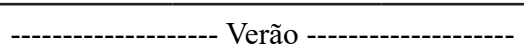 } & \multicolumn{2}{|c|}{ 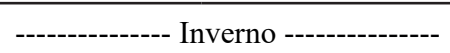 } & \multirow{2}{*}{ Total } \\
\hline & Milheto & Milho & Soja & Trigo & Nabo/Azevém & \\
\hline Colembolla & $0^{*}$ & 0 & 0 & 285 & 52 & 337 \\
\hline Hymenoptera & 61 & 35 & 141 & 4 & 36 & 277 \\
\hline Diptera & 55 & 34 & 8 & 23 & 90 & 210 \\
\hline Coleoptera & 33 & 24 & 50 & 1 & 18 & 126 \\
\hline Orthoptera & 10 & 10 & 66 & 3 & 6 & 95 \\
\hline Pulmonata & 5 & 8 & 13 & 3 & 0 & 29 \\
\hline Araneae & 1 & 0 & 1 & 0 & 0 & 2 \\
\hline Blattodea & 0 & 0 & 2 & 0 & 0 & 2 \\
\hline Lepidoptera & 0 & 0 & 0 & 0 & 3 & 3 \\
\hline Hemiptera & 0 & 0 & 1 & 0 & 0 & 1 \\
\hline Scolopendrida & 0 & 0 & 1 & 0 & 0 & 1 \\
\hline Total & 165 & 111 & 283 & 319 & 205 & 1.083 \\
\hline
\end{tabular}

* Valores referentes às somas de quatro armadilhas por área.

A cobertura vegetal influencia a distribuição de comunidades de colêmbolos edáficos (Chauvat et al., 2003; Silva et al., 2013). Áreas agrícolas bem manejadas e com boa disponibilidade de recursos tendem a ter uma maior dominância deste grupo (Bedano et al., 2016). Entretanto, além das condições do solo, efeitos externos como a variação sazonal também exercem influência sobre este grupo. Sabe-se que organismos da mesofauna são mais afetados pela variação sazonal do que os organismos da macrofauna e que as variações na temperatura e na precipitação influenciam diretamente sua abundância (Wu \& Wang, 2019).

A ordem Hymenoptera foi segunda mais abundante no estudo, sendo mais frequente nas culturas de verão: soja (48\%), milheto (41\%) e milho (32\%) (Figura 2). Os himenópteros, que na fauna edáfica são representados principalmente pelas formigas, geralmente são dominantes na maioria dos ecossistemas terrestres (Cividanes et al., 2009; Scoriza, 2016). A riqueza de formigas tende a aumentar em ambientes mais complexos e com diversidade vegetal maior, devido à maior disponibilidade de nichos (Rocha et al., 2015), assim como temperaturas mais altas favorecem o aumento da abundância de alguns gêneros específicos (Haddad et al., 2012). A qualidade nutritiva da cobertura vegetal influencia diretamente sobre a presença de formigas, podendo este táxon representar mais de $60 \%$ da macrofauna presente em cultivos de soja (Fidelis et al., 2015).

A ordem Diptera é caracterizada como temporária no solo e não apresenta funcionalidade conhecida. Entretanto, os dípteros foram a terceira ordem mais abundante e foram amostrados em todas as coberturas vegetais. Esses organismos estão presentes em praticamente todos os habitats e ocupam diversos nichos alimentares (Camargo, 2018).

Os coleópteros foram a quarta ordem mais abundante e encontrados em todas as coberturas vegetais. A frequência do grupo foi diferente entre as áreas avaliadas, perfazendo $22 \%$ dos indivíduos no milho, $17 \%$ no milheto, $18 \%$ na soja. Nas coberturas de inverno sua frequência 
foi menor, representando somente $9 \%$ dos indivíduos no consórcio de nabo/azevém e $0,3 \%$ no trigo. Os coleópteros são extremamente comuns em solos brasileiros e apresentam papel importante na qualidade física e química do solo (Portilho et al., 2011).

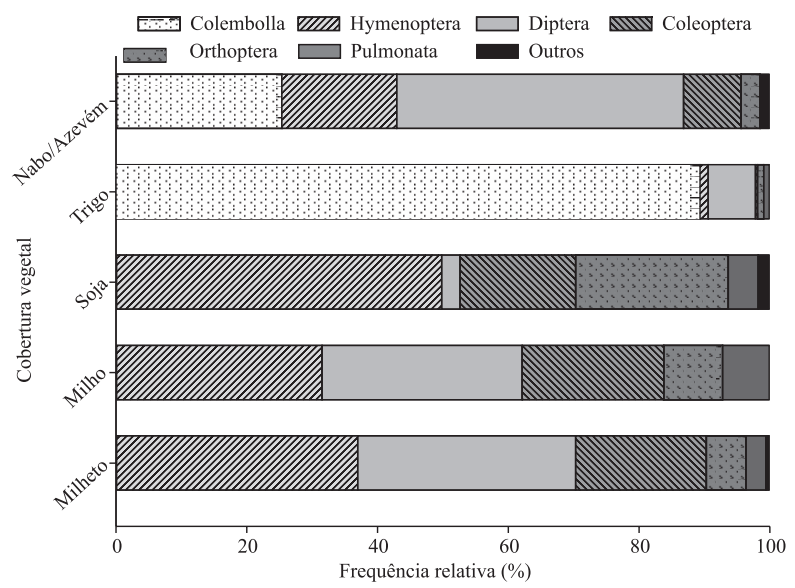

Figura 2 - Frequência relativa dos táxons de invertebrados edáficos amostrados em cinco diferentes coberturas vegetais agrícolas em dois períodos sazonais (milheto, milho, soja no verão e trigo e nabo/azevém no inverno) no município de Santo Ângelo/RS. O agrupamento "Outros" contempla táxons com frequências inferiores à 2\% (Araneae, Blattodea, Lepidoptera, Hemiptera e Scolopendrida). Valores referentes às somas de quatro armadilhas por área.

Os ortópteros foram expressivamente mais frequentes na área cultivada com soja, com $23 \%$ do total dos indivíduos. Nas outras áreas avaliadas representaram 9\% no milho, $10 \%$ no milheto, $3 \%$ no consórcio de nabo/ azevém e $0,9 \%$ no trigo. Estes artrópodes fitófagos são conhecidos como insetos-praga na agricultura, causando expressivos danos em lavouras de grãos (Andaló et al., 2018). Sua explosão demográfica em geral está associada à distúrbios ambientais, monocultivos e ausência de predadores naturais (Graciani et al., 2005). Porém, em ambientes onde é realizado seu controle a ausência também traz distúrbios ao meio ambiente, visto que esse grupo é uma das bases da cadeia alimentar de várias espécies de aves (Fonderflick et al., 2014).

Os grupos Hymenoptera, Coleoptera e Orthoptera decaíram expressivamente nas coberturas vegetais de trigo e consórcio de nabo/azevém. Pode-se associar esse fato à diferença entre as temperaturas e precipitação nos dois períodos amostrais, visto que em julho obteve-se temperaturas menores e maior pluviosidade (Figura 1). Vários estudos demonstram que insetos são sensíveis às mudanças sazonais (Elie et al., 2018; Wu \& Wang, 2019). Isso pode estar associado a questões fisiológicas, como períodos reprodutivos e diapausa, e a relações fenológicas como oferta de recursos adequados às espécies ao longo do ano (Martins \& Barbeitos, 2000).

A sensibilidade dos invertebrados que habitam o solo tende a refletir os efeitos das práticas de manejo utilizadas, sejam elas conservativas ou não, e do tipo de cobertura vegetal, que limitará o resíduo vegetal deixado que servirá de alimento e abrigo. Esses fatores podem influenciar do ponto de vista da estrutura e fertilidade do solo (Lavelle et al., 1994; Assad, 1997). A maior riqueza de táxons avaliada se deu na cobertura vegetal de soja (Tabela 2), visto que das 11 ordens amostradas, nove foram encontradas nessa área. Este resultado pode estar associado ao fato de esta ser a única cobertura vegetal leguminosa avaliada, visto que as demais são gramíneas (trigo, milheto, milho, azevém) e uma brássica (nabo). Entretanto, a maior riqueza no cultivo de soja não refletiu em maior diversidade avaliado pelo índice de Shannon, que foi maior para os cultivos de milho, milheto e nabo/azevém (Tabela 2).

Tabela 2 - Índices de biodiversidade de invertebrados edáficos amostrados em cinco diferentes coberturas vegetais agrícolas em dois períodos sazonais (milheto, milho, soja no verão e trigo e nabo/azevém no inverno) no município de Santo Ângelo/RS.

\begin{tabular}{lccccc}
\hline \multirow{2}{*}{ Índice } & ------- & Verão ---c--- & ----- Inverno ------ \\
\cline { 2 - 6 } & Milheto & Milho & Soja & Trigo & $\begin{array}{c}\text { Nabo/ } \\
\text { Azevém }\end{array}$ \\
\hline Riqueza & 6 & 5 & 9 & 6 & 6 \\
Abundância & 165 & 111 & 283 & 319 & 205 \\
Simpson (1-D) & 0,71 & 0,75 & 0,66 & 0,20 & 0,70 \\
Shannon (H') & 1,36 & 1,46 & 1,33 & 0,45 & 1,39 \\
Pielou (J) & 0,76 & 0,91 & 0,61 & 0,25 & 0,78 \\
\hline
\end{tabular}

*Valores referentes à soma de quatro armadilhas por área.

As gramíneas são capazes de produzir grandes quantidades de matéria seca (Oliveira et al., 2013), o que pode justificar os maiores índices de Shannon quando da sua presença. Além disso, os resíduos das coberturas vegetais dessa família são mais lentamente decompostos 
no solo devido à sua elevada relação carbono:nitrogênio $(\mathrm{C}: \mathrm{N})$, mantendo o habitat favorável à fauna edáfica. Por outro lado, as leguminosas apresentam maior qualidade de resíduo em relação às gramíneas, entretanto, sua menor relação $\mathrm{C}: \mathrm{N}$ tende a proporcionar baixa persistência sobre o solo em função da rápida decomposição (Aita \& Giacomini, 2003).

A maior abundância de organismos foi observada na cobertura vegetal do trigo, seguido da soja, do consórcio nabo/azevém, do milheto e do milho. Com os resultados obtidos através do índice de Simpson, foi possível observar que o trigo foi também a cobertura vegetal mais dominada (Tabela 2). Estes resultados se dão devido à abundância da ordem Colembolla, que se sobressaiu expressivamente em relação as demais ordens. A cobertura vegetal de milho teve a comunidade edáfica mais equilibrada (Pielou) e menos dominada (Simpson).

Solos cultivados com milheto e nabo/azevém mostraram-se semelhantes quanto à riqueza, porém diferentes em se tratando da composição da comunidade edáfica. $\mathrm{O}$ milheto é uma excelente alternativa para a produção de palhada na cobertura de solos, produzindo crescimento rápido e boa produção de biomassa (Pacheco et al., 2011). Já os cultivos consorciados, como é o caso do nabo/azevém, apresentam uma maior capacidade de contribuir com o restabelecimento da fauna edáfica (Silva et al., 2013). A serapilheira em manejos consorciados representa um recurso mais diverso e contribui na manutenção das taxas de infiltração de água e o acúmulo de matéria orgânica (Agostinetto et al., 2000). Isso favorece diretamente a fauna do solo e, além disso, incrementa a oferta de $\mathrm{N}$ e de matéria seca para os sistemas de produção subsequentes (Silva et al., 2013).

\section{CONCLUSÕES}

A cobertura vegetal e a sazonalidade afetam diretamente a comunidade de invertebrados edáficos em áreas agrícolas cultivadas no município de Santo Ângelo.

A ordem Colembolla foi a mais representativa no inverno, enquanto que a Hymenoptera foi a mais pronunciada no verão.

As coberturas vegetais com maior potencial de produção de matéria seca de parte aérea (milho, milheto e consórcio nabo/azevém) apresentam maiores índices de diversidade e equabilidade e menores índices de dominância dos organismos da fauna edáfica.

\section{LITERATURA CITADA}

AITA, C.; GIACOMINI, S. Decomposição e liberação de nitrogênio de resíduos culturas de plantas de cobertura de solo solteiras e consorciadas. Revista Brasileira de Ciência do Solo, v.27, p.601-612, 2003. DOI: 10.1590/S010006832003000400004.

ALTIERI, M.; SILVA, E.N.; NICHOLLS, C.I. O Papel da Biodiversidade no Manejo Integrado de Pragas. Ribeirão Preto: Holos, 2003. 226p.

ANDALÓ, V.; ROSSATI, K.P.; CARVALHO, F.J. et al. Entomopathogenic nematodes for the control of Gryllus sp. (Orthoptera: Gryllidae) under laboratory and field conditions. Arquivos do Instituto Biológico, v.85, e0442017, p.1-7, 2018. DOI: 10.1590/1808-1657000442017.

ANTONIOLLI, Z.I.; CONCEIÇÃO, P.C.; BÖCK, V. et al. Método alternativo para estudar a fauna do solo. Ciência Florestal, v.16, n.4, p.407-417, 2006. DOI: 10.5902/198050981922.

ARAÚJO, G.G.L. Cultivo estratégico de forrageiras anuais e perenes, visando a suplementação de caprinos e ovinos no semi-árido do Nordeste. Petrolina: Embrapa Semiárido, 2001. 4p.

ASSAD, M.L.L. Fauna do solo. In: VARGAS, M.A.T.; HUNGRIA, M.A.T. (Ed.) Biologia dos solos dos Cerrados. Planaltina: EMBRAPA-CPAC, 1997. p.363-443.

AGOstinetTO, D.; FERREIRA, F.B.; STOCH, G. et al. Adaptação de espécies utilizadas para cobertura de solo no sul do Rio Grande do Sul. Revista Brasileira de Agrociência, v.6, n.1, p.47-52, 2000.

BEDANO, J.C.; DOMÍNGUEZ, A.; AROLFO, R. et al. Effect of good agricultural practices under no-till on litter and soil invertebrates in areas with different soil types. Soil and Tillage Research, v.158, p.100-109, 2016. DOI: 10.1016/j.still.2015.12.005.

BROWN, G.G.; SAUTTER, K.D. Biodiversity, conservation and sustainable management of soil animals: the XV International Colloquium on Soil Zoology and XII International Colloquium on Apterygota. Pesquisa Agropecuária Brasileira, v.44, p.1-9, 2009. DOI: 10.1590/ S0100-204X2009000800001

BUZZI, Z.J. Entomologia didática, 6.ed. Curitiba: UFPR, 2013. 579p.

CALONEGO J.C.; SANTOS, C.H.; TIRITAN, C.S. et al. Estoques de carbono e propriedades físicas de solos submetidos a diferentes sistemas de manejo. Revista Caatinga, v.25, n.2, p.128-135, 2012. 
CAMARGO, A.J.A. Ordem Diptera. 2018. In: https:// www.embrapa.br/cerrados/colecao-entomologica/diptera (acessado em 14 de Agosto de 2019).

CHAUVAT, M.; ZAITSEV, A.S.; WOLTERS, V. Successional changes of Collembola and soil microbiota during forest rotation. Oecologia, v.137, n.2, p.269-276, 2003. DOI: $10.1007 / \mathrm{s} 00442-003-1310-8$.

CIVIDANES, F.J.; BARBOSA, J.C.; MARTINS, I.C.F. et al. Diversidade e distribuição espacial de artrópodes associados ao solo em agroecossistemas. Bragantia, v.68, n.4, p.991-1002, 2009. DOI: 10.1590/S000687052009000400020 .

CÓRDOVA, M.; CHAVES, C.L.; COIMBRA, S.M. Fauna do solo x vegetação: estudo comparativo da diversidade edáfica em áreas de vegetação nativa e povoamentos de pinus sp. Geoambiente on-line, v.12, p.1-12, 2009. DOI: 10.5216/rev.\%20geoambie.v0i12.25981.

CORREIA, M.E.F. Relações entre a diversidade da fauna de solo e o processo de decomposição e seus reflexos sobre a estabilidade dos ecossistemas. Seropédica: Embrapaagrobiologia, 2002. 33p. (Embrapa Agrobiologia. Documento, 156).

DAMÉ, P.R.V.; QUADROS, F.L.F.; KERSTING, C.E.B. et al. Efeitos da queimada seguida de pastoreio ou diferimento sobre o resíduo, temperatura do solo e mesofauna de uma pastagem natural. Ciência Rural, v.26, n.3, p.391-396, 1996. DOI: $10.1590 / \mathrm{S} 0103-84781996000300008$.

DOMÍNGUEZ, A.; JIMÉNEZ, J.J.; ORTÍZA, C.E. et al. Soil macrofauna diversity as a key element for building sustainable agriculture in Argentine Pampas. Acta Oecologica, v.92, p.102-116, 2018. DOI: 10.1016/j. actao.2018.08.012.

ELIE, F.; VINCENOT, L.; THIERRY, B. et al. Soil fauna as bioindicators of organic matter export in temperate forests. Ecologia Florestal e Gestão, v.429, p.549-557, 2018. DOI: 10.1016/j.foreco.2018.07.053.

EMPRESA BRASILEIRA DE PESQUISA AGROPECUARIA - EMBRAPA. Sistema brasileiro de classificação de solos. 5.ed. Brasília: Embrapa, 2018. 356p.

FIDELIS, R.R.; GONZAGA, L.A.M.; SILVA, J. et al. Macrofauna edáfica em consórcio de sorgo e soja sob incremento de nitrogênio na gramínea. Revista Verde de Agroecologia e Desenvolvimento Sustentável, v.10, n.1, p.4-7, 2015. DOI: 10.18378/rvads.v10i1.2817.

FONDERFLICK, J.; BESNARD, A.; BEURET, A. et al. The impact of grazing management on Orthoptera abundance varies over the season in Mediterranean steppe- like grassland. Acta Oecologica, v.60, p.7-16, 2014. DOI: 10.1016/j.actao.2014.07.001.

GATIBONI, L.C.; COIMBRA, J.L.M.; WILDNER, L.P. et al. Modificações na fauna edáfica durante a decomposição da palhada de centeio e aveia preta, em sistema plantio direto. Biotemas, v.22, n.2, p.2-3, 2009. DOI: $10.5007 / 2175-7925.2009 \mathrm{v} 22 \mathrm{n} 2 \mathrm{p} 45$.

GRACIANI, C.; GARCIA, F.R.M.; COSTA, M.K.M. Análise faunística de gafanhotos (Orthoptera, Acridoidea) em fragmento florestal próximo ao Rio Uruguai, município de Chapecó, Santa Catarina. Biotemas, v.18, n.2, p.7-10, 2005. DOI: $10.5007 / \% 25 \mathrm{x}$.

HADDAD, G.Q.; CIVIDANES, F.J.; MARTINS, I.C.F. et al. Population fluctuations of Formicidae (Hymenoptera) and Araneae (Arachnida) in two tillage systems in the region of Guaíra-SP. Florida Entomologist, v.95, n.4, p.1012-1018, 2012. DOI: 10.1653/024.095.0429.

HAMMER, O.; HARPER, D.A.T.; RYAN, P.D. PAST Paleontological Statistics software package for education and data analysis. Palaeontologia Electronica, v.41, n.1, p.1-9, 2001.

HÖFER, H.; HANAGART, W.; GARCIA, M. et al. Struture and function of soll fauna communities in Amazonian anthropogenic and natural ecosystems. Euro Journal of Soil Biology, v.37, p.229-235, 2001. DOI: 10.1016/S11645563(01)01089-5.

INSTITUTO RIO GRANDENSE DO ARROZ - IRGA. Médias Climatológicas Santo Ângelo. In: https://irga. rs.gov.br/medias-climatologicas (acessado em 15 de Junho de 2019)

JIANG, Y.; MA, N.; CHEN, Z. et al. Soil macrofauna assemblage composition and functional groups in no-tillage with corn stover mulch agroecosystems in a Mollisol area of northeastern China. Applied Soil Ecology, v.128, p.6170, 2018. DOI: 10.1016/j.apsoil.2018.04.006.

LAVELLE, P.; DANGERFIELD, M.; FRAGOSO, C. et al. The relationship between soil macrofauna and tropical soil fertility, in the biological management of tropical soil fertility. In: WOOMER, P.L.; SWIFT, M.J. (Ed.) The biological management of tropical soil fertility. Chichester: Wiley, 1994. p.137-169.

MARTINS, R.P.; BARBEITOS, M.S. Adaptações de insetos a mudanças no ambiente: ecologia e evolução da diapausa. Oecologia Brasiliensis, v.8, p.149-192, 2000. DOI: $10.4257 /$ oeco.2000.0801.06.

MOREIRA, F.M.S.; CARES, J.E.; ZANETTI, R. et al. $O$ ecossistema solo. Lavras: UFLA, 2013. 351p. 
MOREIRA, F.M.S.; HUISIN, J.; BIGNELL, D.E. Manual de Biologia dos Solos Tropicais. Amostragem e Caracterização da Biodiversidade. 1 ed. Lavras UFLA, 2010. 367p.

NUNES, L.A.P.L.; SILVA, D.I.B.; ARAÚJO, A.S.F. et al. Caracterização da fauna edáfica em sistemas de manejo para produção de forragens no Estado do Piauí. Revista Ciência Agronômica, v.43, n.1, p.30-37, 2012. DOI: 10.1590/S1806-66902012000100004.

ODUM, E.P., BARRETT, G.W. Fundamentos da ecologia. 1 ed. Rio de Janeiro: Thomson Learning, 2007. 612p.

OLIVEIRA, E.R.; MONÇÃO, F.P.; GOES, R.H.T.B. et al. Degradação ruminal da fibra em detergente neutro de gramíneas do gênero Cynodon spp em quatro idades de corte. Agrarian, v.6, n.20, p.205-214, 2013.

PACHECO, L.P.; LEANDRO, W.M.; MACHADO, P.D.A. et al. A produção de fitomassa e acúmulo e liberação de nutrientes por plantas de cobertura na safrinha. Pesquisa Agropecuária Brasileira, v.46, p.17-25, 2011. DOI: 10.1590/S0100-204X2011000100003.

PORTILHO, I.I.R.; CREPALDI, R.A.; BORGES, C.D. et al. Fauna invertebrada e atributos físicos e químicos do solo em sistemas de integração lavoura-pecuária. Pesquisa Agropecuária Brasileira, v.46, p.1310-1320, 2011. DOI: 10.1590/S0100-204X2011001000027.

ROCHA, W.O.; DORVAL, A.; FILHO, O.P. et al. Formigas (Hymenoptera: Formicidae) bioindicadoras de degradação ambiental em Poxoréu, Mato Grosso, Brasil. Floresta e
Ambiente, v.22, n.1, p.88-98, 2015. DOI: 10.1590/21798087.0049 .

SCORIZA, R.N. Efeito do cultivo de plantas de cobertura sobre a fauna edáfica. Revista Brasileira de Agroecologia, v.11, n.4, p-5-9, 2016.

SILVA, R.F.; AQUINO, A.M.; MERCANTE, F.M. et al. Macrofauna invertebrada do solo sob diferentes sistemas de produção em Latossolo da região do Cerrado. Pesquisa Agropecuária Brasileira, v.41, p.697-704, 2006. DOI: 10.1590/S0100-204X2006000400022.

SILVA, R.F.; CORASSA, G.M.; BERTOLLO, G.M. et al. Fauna edáfica influenciada pelo uso de culturas e consórcios de cobertura do solo. Pesquisa Agropecuária Tropical, v.43, n.2, p.130-137, 2013.

VIEIRA, L.M.; MENDEL, S.M. Riqueza de artrópodes relacionada à complexidade estrutural da vegetação: uma comparação entre métodos. In: VENTICINQUE, E.; HOPKINS, M. (Ed.). Ecologia de campo: curso de campo. Campo Grande: UFMS, 2002.

WU, P.; WANG, C. Differences in spatiotemporal dynamics between soil macrofauna and mesofauna communities in forest ecosystems: The significance for soil fauna diversity monitoring. Geoderma, v.337, p.266-272, 2019. DOI: 10.1016/j.geoderma.2018.09.031.

YIN, X.; MA, C.; HE, H. et al. Distribution and diversity patterns of soil fauna in different salinization habitats of Songnen Grasslands, China. Applied Soil Ecology, v.123, p.375-383, 2018. DOI: 10.1016/j.apsoil.2017.09.034.

Recebido para publicação em 10/11/2019, aprovado em 18/02/2020 e publicado em 30/04/2020. 